\title{
A Study on Catalysis by Ferrospinels for Preventing Atmospheric Pollution from Carbon Monoxide
}

\author{
Chennampilly Ummer Aniz, Thengumthanam Damodaran Radhakrishnan Nair ${ }^{*}$ \\ School of Chemical Sciences, Payyanur Campus, Kannur University, Kerala, India. \\ E-mail: tdrnair@rediffmail.com \\ Received July 19, 2011; revised August 22, 2011; accepted October 9, 2011
}

\begin{abstract}
Ferrospinel catalyst samples containing Nickel, Cobalt and Copper have been synthesized by room temperature co-precipitation route and have been found to be effective for the oxidative removal of carbon monoxide from automobile exhaust gases even at relatively lower temperatures (cold-start). These catalyst materials have been characterized by modern physico-chemical techniques such as XRD, TG, BET-BJH and SEM etc. Nitrogen adsorption studies shows the samples are mesoporous in nature with pore diameter of $5-10 \mathrm{~nm}$. The catalytic efficiencies of these materials of having various compositions have been tested in a series of temperature programmed oxidation reactions involving carbon monoxide and the results discussed.
\end{abstract}

Keywords: Catalysis, Ferrospinels, Mesoporous, Atmospheric Pollution, Carbon Monoxide Oxidation

\section{Introduction}

Protection of the environment and prevention of atmospheric pollution from gaseous pollutants continues to be a challenging task for chemists. The present study is aimed at providing measures to ensure protection of the atmosphere from automobile exhaust pollution due to carbon monoxide, using some ferrospinel preparations as green catalysts for oxidative purification. These catalysts are ferrite spinels containing varying proportions of $\mathrm{Ni}$, $\mathrm{Co}$ and $\mathrm{Cu}$ which have been synthesized by room temperature co-precipitation [1] and characterized before use. The catalytic efficiencies of these materials have been tested at various temperatures for the oxidative removal of carbon monoxide (CO), from automobile exhaust gases, which constitute the major polluting factor in atmospheric pollution. The catalyst materials prepared have been characterized by methods like BET-BJH, TG, XRD, Ammonia TPD etc. The fact that these catalyst materials are cheaper compared to the platinum group metals being used in a big way in the field make the present study quite significant.

Spinel ferrites containing $\mathrm{Ni}, \mathrm{Co}$, and $\mathrm{Cu}$ have technological significance as catalysts due to their special electronic and magnetic properties [2]. It has earlier been observed that the presence of these metals in ferrite spinel lattices strongly modify their stability and redox properties [3].

\section{Experimental}

\subsection{Synthesis of the Spinel Catalysts}

Three samples of simple spinel ferrites, $\mathrm{AFe}_{2} \mathrm{O}_{4}(\mathrm{~A}=\mathrm{Ni}$, $\mathrm{Co} \& \mathrm{Cu})$ and three samples of mixed ternary spinel ferrites, $\mathrm{Ni}_{\mathrm{x}} \mathrm{Co}_{\mathrm{y}} \mathrm{Cu}_{\mathrm{z}} \mathrm{Fe}_{2} \mathrm{O}_{4}(\mathrm{x}=0.6 ; \mathrm{y}=\mathrm{z}, \mathrm{y}=0.6 ; \mathrm{x}=\mathrm{z}, \mathrm{z}=$ $0.6 ; \mathrm{x}=\mathrm{y}$, where $\mathrm{x}+\mathrm{y}+\mathrm{z}=1$ ) have been prepared. Metal hydroxides were co precipitated from an aqueous homogenous mixture containing 0.17 moles of ferric nitrate and its half the moles of $\mathrm{Cu} / \mathrm{Ni} / \mathrm{Co}$ nitrate mixtures depends on the sample composition. The precipitating alkali, aqueous $\mathrm{NaOH}$ of $5.3 \mathrm{M}$, was added drop wise from a micro burette with continuous stirring to a final $\mathrm{pH}$ of 10 . These precipitates were aged for $12 \mathrm{hrs}$, filtered, washed off nitrates and alkali and dried at $110^{\circ} \mathrm{C}$ for $10 \mathrm{hrs}$. These powders were calcined at $300^{\circ} \mathrm{C}$ for 4 hrs in air muffle to allow spinel phase formation. The mixed ternary ferrites are given the code "xyz" where xyz refer to the mole ratio $\mathrm{x}: \mathrm{y}: \mathrm{z}$ in the formula, $\mathrm{Ni}_{\mathrm{x}} \mathrm{Co}_{\mathrm{y}-}$ $\mathrm{Cu}_{\mathrm{z}} \mathrm{Fe}_{2} \mathrm{O}_{4}$. All the samples were calcined at $500^{\circ} \mathrm{C}$ also separately for specific use.

\subsection{Characterization of Samples}

The samples of ferrospinels have been characterized by different physico-chemical methods like XRD, BET surface area, Ammonia-Temperature Programmed Desorp- 
tion (TPD), ICP-AES, TG/DTG, etc. The results of the BET surface area and ammonia-TPD data are given in Tables 1 and 2 respectively. TPD studies were done using Pulse Chemisorb 2705 from Micromeritics. Samples were degassed in helium in a quartz reactor, at $200^{\circ} \mathrm{C}$, and then cooled to ambient temperature. $5 \% \mathrm{NH} 3$ in helium gas (from Bheruka gases, Bangalore) is admitted to the sample for $15 \mathrm{~min}$ to saturate the sample. Physisorbed ammonia was purged away, keeping the sample at $100^{\circ} \mathrm{C}$. Sample temperature was raised to $700^{\circ} \mathrm{C}$ at a rate of $10^{\circ} \mathrm{C} / \mathrm{min}$ measuring the outlet desorbed ammonia using a calibrated TCD.

Nitrogen adsorption-desorption measurements were done on a volumetric Micromeritics Tristar apparatus at Liquid N2 temperature, $77.35 \mathrm{~K}$. On an average 33 points were taken for each sample. The average mass of the sample was $0.3 \mathrm{~g}$. Pore size distributions were calculated using $\mathrm{BJH}$ method and surface areas were taken from BET isotherms.

The temperature-programmed reduction studies (TPR) were performed in Micromeritics PulseChemisorb-2705, which incorporates a thermal conductivity detector (TCD). Samples were activated/surface-cleaned in helium at $200^{\circ} \mathrm{C}$ for 30 minutes, then cooled to ambient temperatures. The reactive gas composition was $10 \%$ balance $\mathrm{N}_{2}$, its consumption was measured while heating the sample up to $750^{\circ} \mathrm{C}$ at a rate of $10^{\circ} \mathrm{C} / \mathrm{min}$.

\subsection{Kinetic and Catalytic Studies}

Kinetic and catalytic reaction studies of carbon monoxide oxidation have been done with all the catalyst samples, granulated to $16 \times 20$ mesh sizes after shaping to cylindrical tablets. $0.5 \mathrm{~g}$ of the activated catalyst samples were supported between glass wool plugs and flanked by inert porcelain beads in the middle of a specially designed quartz reactor, the flow diagram is as given in Figure 1.

The inlet gas was calibrated mixture gas of $6 \% \mathrm{~V} / \mathrm{V}$ of oxygen, $1 \% \mathrm{~V} / \mathrm{V}$ of carbon monoxide and the rest nitrogen. Gas flow was adjusted to a space velocity of 28,800 $\mathrm{h}^{-1}$. The reaction has been studied at four reaction temperatures of $80^{\circ} \mathrm{C}, 100^{\circ} \mathrm{C}, 120^{\circ} \mathrm{C}$ and $140^{\circ} \mathrm{C}$. The catalyst samples have been activated at $300^{\circ}$ for 1 hour prior to reaction studies. The details are given in Table 3 . The $\mathrm{CO}$ and $\mathrm{CO}_{2}$ in the outlet gas were separated using "Pouropack" packed column followed by converting to methane by the "methanator" containing the Sud Chemie $\mathrm{Ni}$-catalyst working at $400^{\circ} \mathrm{C}$ and finally detected separately by GC-FID. The percentage conversion was calculated using the equation:

$$
\% \text { Conversion }=\left(\mathrm{C}_{\mathrm{co}}-\mathrm{C}^{\prime}{ }_{\mathrm{co}}\right) / \mathrm{C}_{\mathrm{co}} \times 100
$$

where, $C_{c o}$ and $C_{c o}$, are the $\%$ inlet and outlet carbon

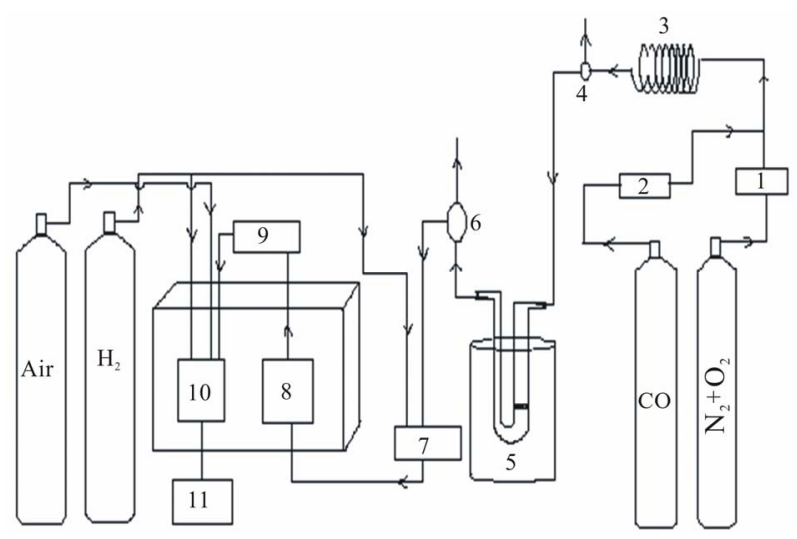

Figure 1. Flow diagram of the reactor $\&$ the analytical set up for carbon monoxide oxidation studies. (1. Mass flow controller for $\mathrm{N}_{2}-\mathrm{O}_{2}$ gas mixture. 2. Mass flow controller for CO. 3. Loop for mixing the gases. 4. Sampling point for inlet analysis. 5. U-tube glass reactor in the electric furnace with PID controller. 6. Outlet for measuring total gas flow. 7. Gas sample injector. 8. GC column. 9. Methanator with Sud-Chemie methanation catalyst. 10. GC-FID detector. 11. Data processor.)

monoxide compositions respectively.

Activation energies for the $\mathrm{CO}$ oxidation reactions were calculated using the conversion data at various reaction temperatures. The catalytic activity of the selected samples were tested for CO-oxidation reaction continuously for around $60 \mathrm{hrs}$ at a constant temperature of $125^{\circ} \mathrm{C}$, which is near to its $70 \% \mathrm{CO}$ conversion temperature, $\mathrm{T}_{70}$.

\section{Results and Discussion}

The composition of a few samples has been checked by Inductively Coupled Plasma-Atomic Emission Spectroscopy technique and the results agreed fairly well with theoretically expected $\mathrm{w} / \mathrm{w}$ percentage of the transition elements in them.

TG traces of the catalyst samples are given in Figure 2. Initial weight loss up to $120^{\circ} \mathrm{C}$ is due to the loss of adsorbed water. The samples are thermally stable after $300^{\circ} \mathrm{C}$.

The loss in weight in the region $120^{\circ}$ to $300^{\circ} \mathrm{C}$ could be due to loss of oxygen arising out of structural transformations, beyond that the samples are stable. Hence these catalyst samples are convenient for use in the automobile exhaust systems. The content of surface and total hydroxide groups were calculated from the TG/DTA data $[4,5]$ from the mass loss in two different temperature ranges of $150^{\circ} \mathrm{C}-200^{\circ} \mathrm{C}$ and $150^{\circ} \mathrm{C}-400^{\circ} \mathrm{C}$ respectively.

\subsection{XRD Analysis}

X-ray crystallographic studies show that the first three 
Table 1. Catalyst composition, identification codes, and surface area values.

\begin{tabular}{|c|c|c|c|c|c|c|}
\hline \multirow[b]{2}{*}{ No. } & \multirow{2}{*}{$\begin{array}{c}\text { Composition, } \\
\mathrm{Ni}_{x} \mathrm{Co}_{y} \mathrm{Cu}_{z} \mathrm{Fe}_{2} \mathrm{O}_{4}\end{array}$} & \multirow[b]{2}{*}{ Code (xyz) } & \multirow{2}{*}{$\begin{array}{l}\text { Pore volume } \\
\qquad\left(\mathrm{cm}^{3} / \mathrm{g}\right)\end{array}$} & \multirow{2}{*}{$\begin{array}{l}\text { Average Pore dia } \\
\text { (nm) }\end{array}$} & \multicolumn{2}{|c|}{ Surface area $\left(\mathrm{m}^{2} / \mathrm{g}\right)$} \\
\hline & & & & & $\begin{array}{c}\text { Calcined at } \\
300^{\circ} \mathrm{C}\end{array}$ & $\begin{array}{l}\text { Calcined } \\
\text { at } 500^{\circ} \mathrm{C}\end{array}$ \\
\hline 1 & $\mathrm{NiFe}_{2} \mathrm{O}_{4}$ & 100 & 0.209 & 6.55 & 123 & 53 \\
\hline 2 & $\mathrm{CoFe}_{2} \mathrm{O}_{4}$ & 010 & 0.199 & 10.50 & 81 & 39 \\
\hline 3 & $\mathrm{CuFe}_{2} \mathrm{O}_{4}$ & 001 & 0.241 & 7.07 & 124 & 16 \\
\hline 4 & $\mathrm{Ni}_{0.6} \mathrm{Co}_{0.2} \mathrm{Cu}_{0.2} \mathrm{Fe}_{2} \mathrm{O}_{4}$ & 622 & 0.233 & 5.57 & 149 & 40 \\
\hline 5 & $\mathrm{Ni}_{0.2} \mathrm{Co}_{0.6} \mathrm{Cu}_{0.2} \mathrm{Fe}_{2} \mathrm{O}_{4}$ & 262 & 0.243 & 6.64 & 117 & 56 \\
\hline 6 & $\mathrm{Ni}_{0.2} \mathrm{Co}_{0.2} \mathrm{Cu}_{0.6} \mathrm{Fe}_{2} \mathrm{O}_{4}$ & 226 & 0.203 & 7.51 & 106 & 39 \\
\hline
\end{tabular}

Table 2. Ammonia TPD data on the ferrospinels, $\mathrm{Ni}_{x} \mathrm{Co}_{y} \mathrm{Cu}_{z} \mathrm{Fe}_{2} \mathrm{O}_{4}(x+y+z=1)$ activated at $300^{\circ} \mathrm{C}$.

\begin{tabular}{|c|c|c|c|c|c|}
\hline \multirow[b]{2}{*}{ No. } & \multirow{2}{*}{$\begin{array}{c}\text { Composition } \\
\text { code: } x y z \\
\mathrm{Ni}_{\mathrm{x}} \mathrm{Co}_{\mathrm{y}} \mathrm{Cu}_{\mathrm{z}} \mathrm{Fe}_{2} \mathrm{O}_{4}\end{array}$} & \multicolumn{4}{|c|}{ Ammonia desorbed at various temperatures (mmol/g) } \\
\hline & & $\begin{array}{c}\text { Weak } \\
(100-200)\end{array}$ & $\begin{array}{c}\text { Medium } \\
(200-400)\end{array}$ & $\begin{array}{c}\text { Strong } \\
(400-700)\end{array}$ & Total \\
\hline 1 & $\mathrm{NiFe}_{2} \mathrm{O}_{4}$ & 0.111 & 0.284 & 0.249 & 0.644 \\
\hline 2 & $\mathrm{CoFe}_{2} \mathrm{O}_{4}$ & 0.107 & 0.210 & 0.115 & 0.431 \\
\hline 3 & $\mathrm{CuFe}_{2} \mathrm{O}_{4}$ & 0.186 & 0.362 & 0.156 & 0.704 \\
\hline 4 & 622 & 0.179 & 0.674 & 0.222 & 1.075 \\
\hline 5 & 262 & 0.129 & 0.622 & 0.314 & 1.065 \\
\hline 6 & 226 & 0.108 & 0.402 & 0.131 & 0.641 \\
\hline
\end{tabular}

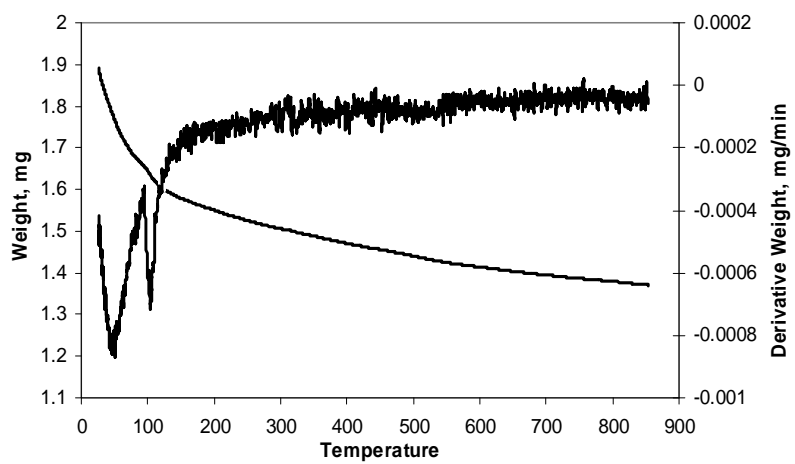

(a)

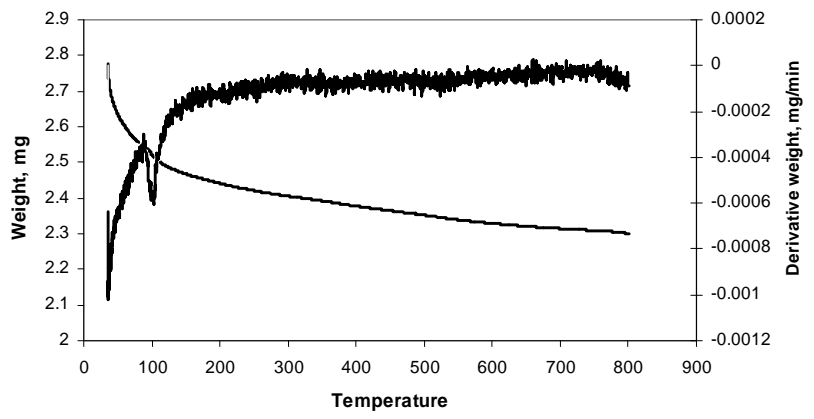

(b)

Figure 2. TG picture of samples (a) 622 and (b) 262.

prominent peaks in the XRD patterns of inverse spinel structures correspond to the hkl values, 311 (100\%), 440 $(60 \%)$ and $220(50 \%)$.

The experimental $d_{h k l}$ values found for the simple ferrites and the mixed ferrites agree very closely with the standard values given in the JCPDS cards for the simple ferrite systems, proving the crystallographic features of the samples. The XRD patterns for the samples 622, 262 and 226 are given in Figure 3. The fact that XRD data of all samples are exactly alike is an expected result and this aspect has been discussed elsewhere $[3,6]$.

\subsection{Nitrogen Adsorption Analysis}

The BET surface area studies of the samples activated at $300^{\circ} \mathrm{C}$ and $500^{\circ} \mathrm{C}$ respectively are given in Table 1 . Among the simple ferrites, nickel and copper ferrites have greater surface area than cobalt ferrite. For the mixed ferrites, the surface area values are more or less the same at an average value of $120 \mathrm{~m}^{2} / \mathrm{g}$. The sample 262 shows an exceptionally high value $149 \mathrm{~m}^{2} / \mathrm{g}$. Calcination to $500^{\circ} \mathrm{C}$ causes decrease in surface area, the decrease being drastic for copper ferrite. The decrease in surface area with increase in calcination temperature is partly due to the completion of dehydration of the sur-

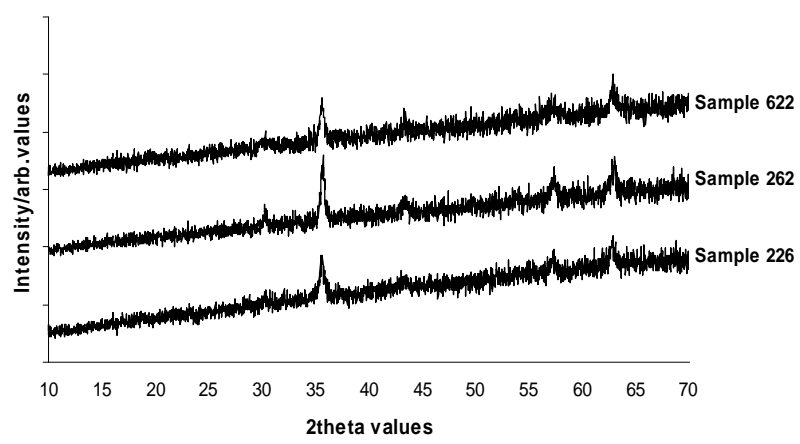

Figure 3. XRD patterns of samples coded 622, 262 and 226. 
face hydroxyl groups, concomitant with the completion of crystallization and growth of crystallite size, and partly due to sintering. Nickel ferrite is retaining the relatively higher surface area with increase of calcination temperature and this property of nickel is expected to support for the higher specific catalytic activity for the resultant mixed ferrites at the higher temperatures. Among the mixed ferrites, the better surface area values of high copper composition samples even after $500^{\circ} \mathrm{C}$ calcination shows the support of nickel and cobalt on retaining the surface area. The high relative surface area of all the samples depends on the preparative methods and high surface area accounts for the increased catalytic activity for the oxidation

Selected representative isotherms have been plotted in Figure 4, the corresponding Barret-Joyner-Halenda (BJ$\mathrm{H})$ pore size distributions were calculated as applied to the adsorption branches. All the samples exhibit nitrogen adsorption/desorption isotherms of the Type IV, showing a well-defined step and hysteresis loop. The P/Po position of reflection points clearly shows that the pore diameter is in the mesopore range, while the broad hysteresis loop reflects some mesopores are disorder in shape. The initial part of the Type IV isotherm is attributed to monolayer-multilayer adsorption since it follows the same path as the corresponding part of a Type II isotherm obtained with the given adsorptive on the same surface area of the adsorbent in a non-porous form. The average pore diameter is estimated to be mainly in a range of $5.0-10.0 \mathrm{~nm}$, while a very negligible portion is also found at relatively larger dimensions. The hystereses appear in the multilayer range of physisorption isotherms and the two branches are nearly parallel over an appreciable range of gas uptake which confirms the H1 type of mesoporous materials. These studies were useful in identifying the nature of the pore structure of the catalysts [7]. The Type H1 loop is often associated with aggregates of nano particles or compacts of uniform spheres in fairly

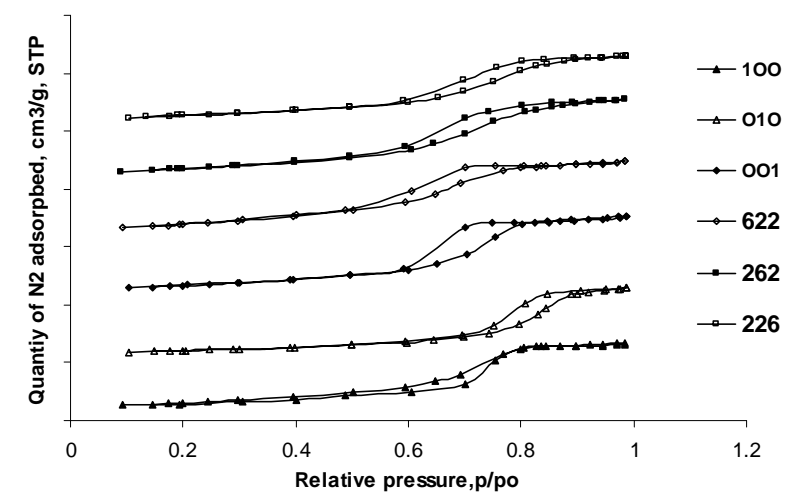

Figure 4. $\mathrm{N}_{2}$-adsorption isotherms (type IV) of spinel ferrite samples-BJH adsorption method. regular array for the obtained samples, since it shows big hysteresis loops at relative pressure between 0.6 and 0.8 , a capillary condensation in nano pores originated from secondary inter-nano particle voids. These observations are in line with the observations from SEM images (Figure 5).

\subsection{Temperature Programmed Reduction Analysis}

In the hydrogen TPR (Figure 6), the first peak characterizes the reduction of +2 valence metal oxides, $\mathrm{Ni} / \mathrm{Co} / \mathrm{Cu}$, along with the reduction of ferric iron to ferrous stage, hematite to magnetite. The second separated peak probably corresponds to the start of $\mathrm{Fe}^{3+}$ to $\mathrm{Fe}^{2+}$ reduction, and the third separated peak stands for the reduction to metallic Iron. In the case of $\mathrm{NiFe}_{2} \mathrm{O}_{4}$, hematite to magnetite peak is observed at $380^{\circ} \mathrm{C}$, where as in $\mathrm{CuFe}_{2} \mathrm{O}_{4}$, it is at around $210^{\circ} \mathrm{C}$. In case of $\mathrm{CoFe}_{2} \mathrm{O}_{4}$, it is further shifted to around $520^{\circ} \mathrm{C}$, and it might only include the reduction of $\mathrm{Co}^{2+}$ to $\mathrm{Co}^{+}$, while the reduction to metallic Co took place at further extreme conditions. It should also be noted that these $\mathrm{Cu}^{2+}$ ions may probably play a significant role in promoting the reduction, even without forming an extended separate metallic copper phase. For the mixed spinel samples, corresponding reduction peaks of $\mathrm{Ni} / \mathrm{Co} / \mathrm{Cu}$ could be seen at respective temperatures depends on their composition. It can be assumed that addition of easily reducible metallic ele-

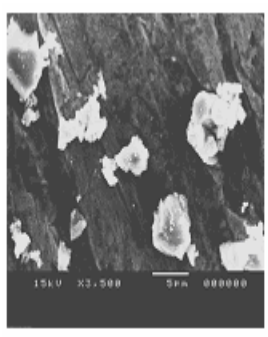

622

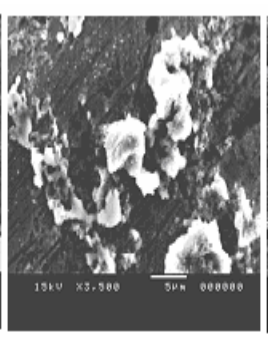

262

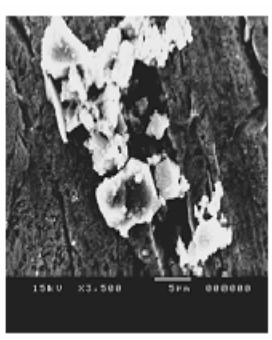

226
Figure 5. SEM photographs of samples 622, 262 and 226.

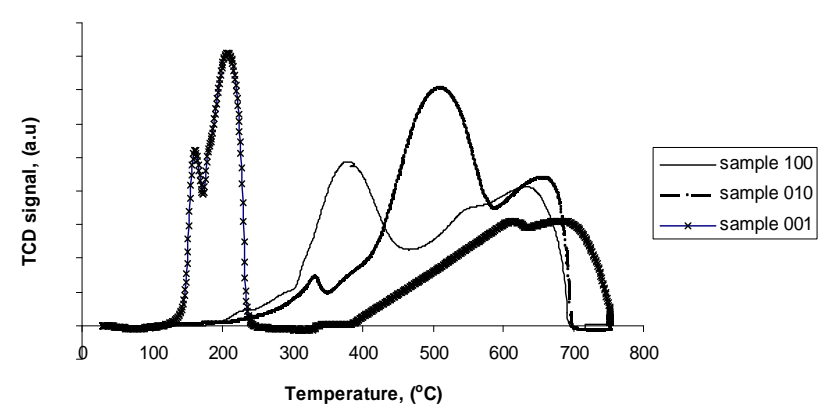

Figure 6. Temperature programmed reduction curves of pure ferrites. 
ments like $\mathrm{Cu}$, may extend the $\mathrm{Fe}^{3+} \Leftrightarrow \mathrm{Fe}^{2+/ 3+}$ reduction to a larger proportion, beyond the stoichiometric ratio. Incorporation of structure stabilizers, like Co, may stabilize iron in the ferric state in an even higher proportion, exceeding the nominal 1:2 ratio. The temperature of the $\mathrm{Fe}^{3+}$ to $\mathrm{Fe}^{3+/ 2+}$ is significantly shifted to lower temperatures in the copper containing samples.

\subsection{Carbon Monoxide Oxidation Studies}

Data in Table 3 shows that copper ferrite among simple ferrites, and sample with code 622 among mixed ferrites, have the maximum specific activities for $\mathrm{CO}$ oxidation at the reaction temperature of $120^{\circ} \mathrm{C}$. However, if the specific activities are divided by the surface area to get intrinsic activities, the maximum activity is for $\mathrm{CoFe}_{2} \mathrm{O}_{4}$ and the sample 262. Figure 7 shows the graphical representation of $\mathrm{CO}$ oxidation performance.

In industrial catalysis, specific activity is more important and, in this sense, sample 622 and copper ferrite are the best catalysts. Intrinsic activity is important in theoretical correlation of activities with the chemical composition, concluding that the best two catalysts are cobalt ferrite (at both activation temperatures) and sample 262, having $70 \%$ of cobalt as the divalent cation. Figure 8 depicts the $\mathrm{CO}$ conversion observed for selected samples after calcination at $500^{\circ} \mathrm{C}$. It is our observation that cobalt ferrite, copper ferrite and mixed ferrites having high percentage of cobalt are excellent catalysts practically in accordance with theoretical requirements. This observation is in line with the surface area values of these samples too. Nickel ferrite and mixed ferrites with high proportion of nickel have generally low activities, owing to their lesser reducible nature irrespective of better surface area values.

It is observed that the catalyst samples prepared and employed have very high $\mathrm{CO}$ conversion abilities amounting to almost $100 \%$ at as low a temperature as $140^{\circ} \mathrm{C}$ which has tremendous possibilities of application

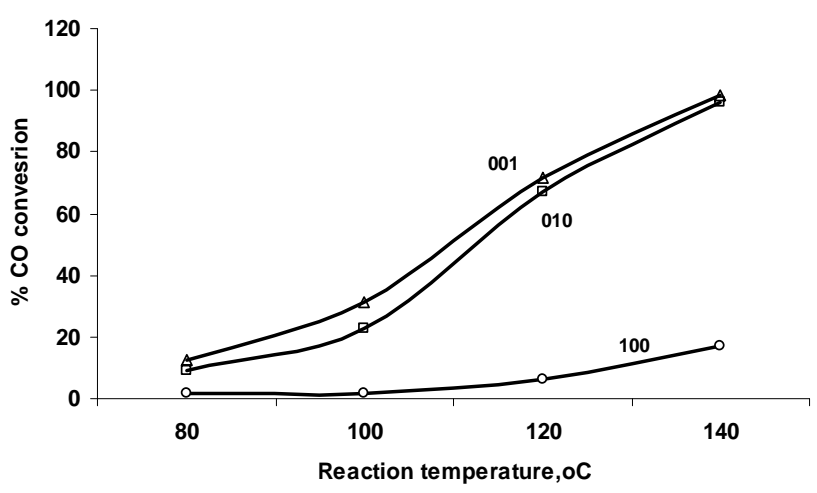

(a)

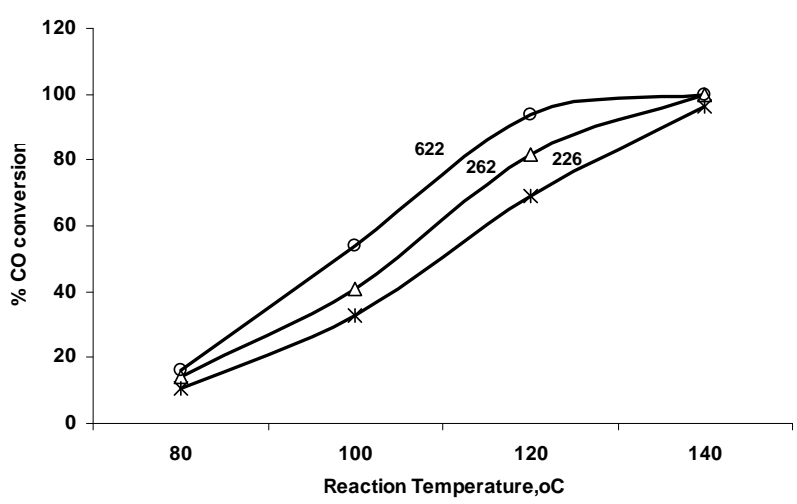

(b)

Figure 7. Carbon monoxide oxidation activity evaluation of ferrite spinel samples calcined at $300^{\circ} \mathrm{C}$ (a) \& (b).

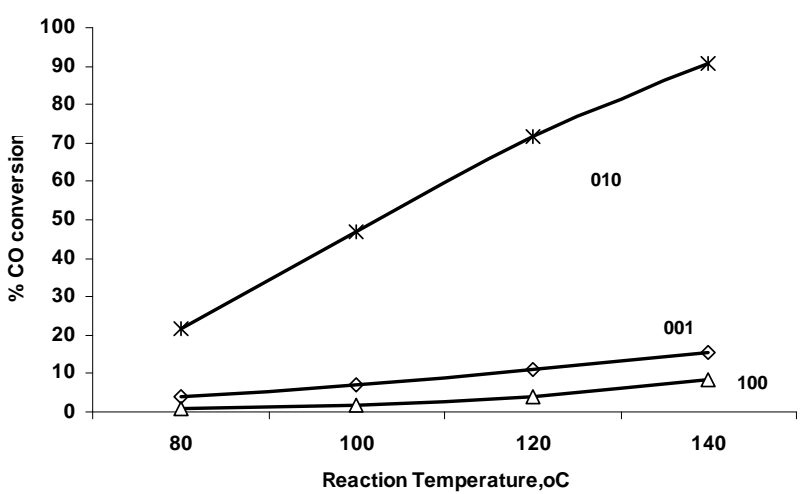

(a)

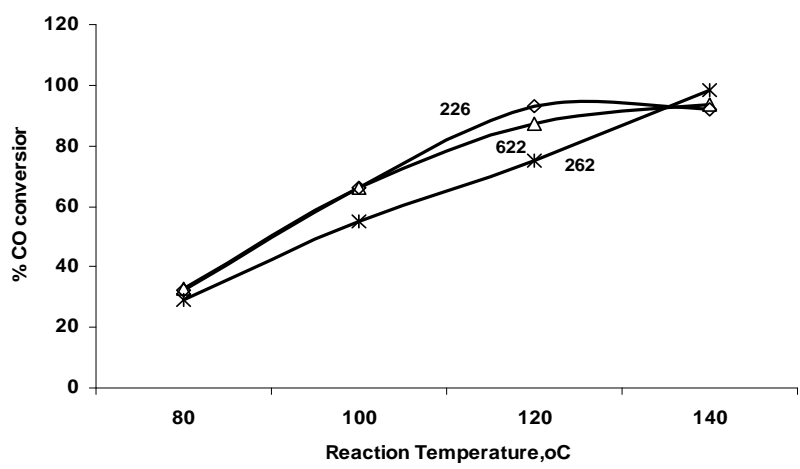

(b)

Figure 8. Carbon monoxide oxidation activity evaluation of ferrite spinel samples calcined at $500^{\circ} \mathrm{C}$ (a) \& (b).

in automobile exhaust purification processes. After the cold start of an automobile engine, a very large fraction of the total emission is left un-reacted [8]. Ordinary exhaust catalysts start functioning only when the temperature rises to about $200^{\circ} \mathrm{C}$. The usual noble metal catalysts require higher reaction temperatures to catalyze $\mathrm{CO}$ or hydrocarbon oxidation. Hence the results of the present investigation have great relevance in automobile exhaust gas puri- 
Table 3. Carbon monoxide oxidation activity for the spinel ferrites.

\begin{tabular}{|c|c|c|c|c|c|c|c|c|c|c|}
\hline \multirow{3}{*}{$\begin{array}{c}\text { Composition } \\
\text { Code: } x y z \\
\mathrm{Ni}_{\mathrm{x}} \mathrm{Co}_{\mathrm{y}} \mathrm{Cu}_{\mathrm{z}} \mathrm{Fe}_{2} \mathrm{O}_{4}\end{array}$} & \multicolumn{10}{|c|}{$\%(\mathrm{v} / \mathrm{v}) \mathrm{CO}$ conversion at various temperatures \& Ea values $\left(\mathrm{KJ} / \mathrm{mol}^{-1}\right)$} \\
\hline & \multicolumn{5}{|c|}{ Samples calcined at $300^{\circ} \mathrm{C}$} & \multicolumn{5}{|c|}{ Samples calcined at $500^{\circ} \mathrm{C}$} \\
\hline & $80^{\circ} \mathrm{C}$ & 100 & 120 & 140 & $\mathbf{E a}$ & $80^{\circ} \mathrm{C}$ & 100 & 120 & 140 & Ea \\
\hline $\mathrm{NiFe}_{2} \mathrm{O}_{4}$ & 1.5 & 1.9 & 6.3 & 17.1 & 50.9 & 1.0 & 1.8 & 4.1 & 8.4 & 43.5 \\
\hline $\mathrm{CoFe}_{2} \mathrm{O}_{4}$ & 8.8 & 22.8 & 67.2 & 95.9 & 50.3 & 21.7 & 47.1 & 71.9 & 90.9 & 28.9 \\
\hline $\mathrm{CuFe}_{2} \mathrm{O}_{4}$ & 12.7 & 31.1 & 71.4 & 98.4 & 42.6 & 3.9 & 7.0 & 10.9 & 15.6 & 28.0 \\
\hline 622 & 16.0 & 54.0 & 93.6 & 99.7 & 37.3 & 32.6 & 66.3 & 87.4 & 93.4 & 32.6 \\
\hline 262 & 14.3 & 41.0 & 81.7 & 99.7 & 40.0 & 29.1 & 54.8 & 75.1 & 98.5 & 29.1 \\
\hline 226 & 10.8 & 32.9 & 69.0 & 96.1 & 44.7 & 32.4 & 66.0 & 93.1 & 91.8 & 32.4 \\
\hline
\end{tabular}

Test conditions: $1 \% \mathrm{CO}$ and $6 \% \mathrm{O}_{2}$ in balance nitrogen, Activation temperature of catalysts at $300^{\circ} \mathrm{C}$, Weight of catalyst loaded: $0.500 \mathrm{~g}$, Space velocity: $28000 \mathrm{~h}^{-1}$.

fication, especially at cold start of an automobile engine.

Ea values are in the range of $25-50 \mathrm{KJ} \cdot \mathrm{mol}^{-1}$ for all the samples, given in Table 3. These values are relatively, low for sample 262 in agreement with its performance, even though these values alone cannot be taken as the direct measure of better catalytic performance.

The $\mathrm{CO}$ oxidation activities of single ferrites, say $\mathrm{NiFe} 2 \mathrm{O} 4, \mathrm{CoFe} 2 \mathrm{O} 4$ and $\mathrm{CuFe} 2 \mathrm{O} 4$ are in the order $\mathrm{NiFe} 2 \mathrm{O} 4<\mathrm{CoFe} 2 \mathrm{O} 4<\mathrm{CuFe2O} 4$, which is in good agreement with the reported study [9].

$\mathrm{CO}$ adsorption probability is relatively higher for $\mathrm{Cu}$ rich samples and it is attributed to their more reducible nature provided with high surface area. Higher surface area provides better adsorption and help in inducing the lattice oxygen to take part in $\mathrm{CO}_{2}$ formation.

The oxidation over mixed metal oxides is proposed to follow a redox mechanism in which the metal ion changes oxidation state on consuming lattice oxygen for $\mathrm{CO}_{2}$ formation. The gaseous oxygen appears to rejuvenate the catalyst surface at octahedral sites and enhanceing oxidation of the adsorbed $\mathrm{CO}[10]$.

$$
\begin{gathered}
\mathrm{CO}_{\text {ads }}+\mathrm{O}_{\text {cat }} \rightarrow \mathrm{CO}_{2 \text { ads }}+* \\
\mathrm{CO}_{2 \text { ads }} \rightarrow \mathrm{CO}_{2(\mathrm{~g})} \\
1 / 2 \mathrm{O}_{2}+* \rightarrow \mathrm{O}_{\text {cat }}
\end{gathered}
$$

where * depicts an oxygen vacancy and $O_{\text {cat }}$ is a surface lattice oxygen, probably $\mathrm{O}^{2-}$.

The relatively higher $\mathrm{CO}$ conversion for copper-rich mixed ferrite samples is due to the influence of copper ions in lowering the reduction temperature of hematite to magnetite, which is more catalytically active than hematite. Presence of Cobalt can stabilize the ferrite structure even at high temperatures. Nickel incorporation helps in protecting the surface area of the ferrites samples even after high temperature treatments, thereby allows the application of these systems for high temperature applications.

Time on stream (TOS) studies (Figure 9) shows the stability of the catalyst samples upon continuous operation. It tells about the fitness of our sample for industrial

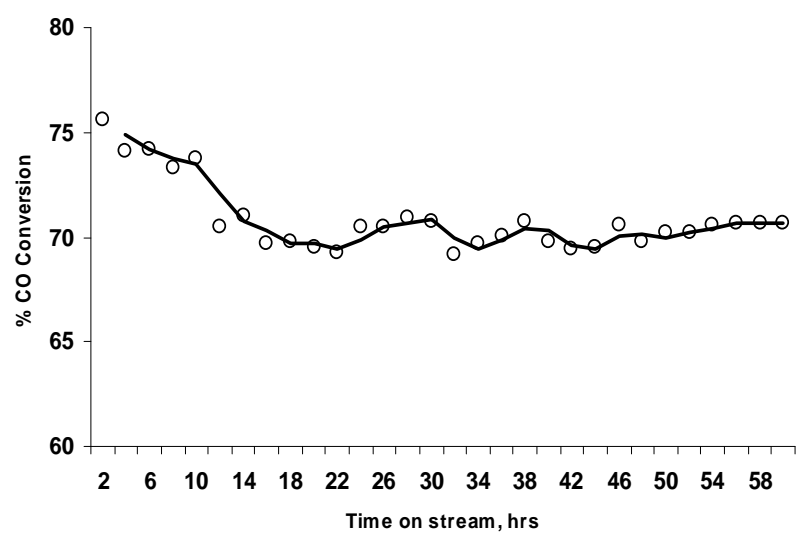

Figure 9. Time on stream study for carbon monoxide oxidation of ferrite spinel sample 262, $\mathrm{Ni}_{0.1} \mathrm{Co}_{0.7} \mathrm{Cu}_{0.7} \mathrm{Fe}_{2} \mathrm{O}_{4}$ calcined at $300^{\circ} \mathrm{C}$, reaction temp $=125^{\circ} \mathrm{C}$.

operations. Except the initial dip, the conversion values (lined out performance) are almost steady. A drop in initial activity is expected for all catalytic systems and it is due to the deactivation of a few unstable highly reactive sites.

\section{Conclusions}

Study of the catalytic activity for the oxidation of $\mathrm{CO}$ using the ferrospinel samples in the temperature range 80 to $140^{\circ} \mathrm{C}$ showed increase in activity with temperature, reaching a limiting value of nearly $100 \%$ conversion of $\mathrm{CO}$ for some samples even at $140^{\circ} \mathrm{C}$. The best two catalyst samples in terms of specific activity are the mixed ferrites coded 622, while in terms of intrinsic activity, $\mathrm{CoFe} 2 \mathrm{O} 4$ and the sample coded 262 are better. It is interesting to note that these spinel samples of mesoporous nature having 5 - $10 \mathrm{~nm}$ pore diameter are effective for furnishing maximum catalytic surface contact for reactant gaseous reactants. Our results suggest that these spinel ferrites can function as efficient pollution abatement catalysts for the protection of the atmospheric en- 
vironment from automobile pollutants and are economically viable.

\section{References}

[1] P. S. Anilkumar, J. J. Shrotri, S. D. Kulkarni, C. E. Desh pande and S. K. Date, "Low Temperature Synthesis of $\mathrm{Ni}_{0.8} \mathrm{Zn}_{0.2} \mathrm{Fe}_{2} \mathrm{O}_{4}$ Powder and Its Characterization," Materials Letters, Vol. 27, No. 6, 1996, p. 293-296. doi:10.1016/0167-577X(96)00010-9

[2] B. S. Rao, K. Sreekumar and T. M. Jyothi, "An Improved Process for the Preparation of a Mixture of Alkylphenols (O-Cresol and 2,6-Xylenol)," Indian Patent No. 2707/98, 1998.

[3] C. G. Ramankutty, S. Sugunan and B. Thomas, "Study of Cyclohexanol Decomposition Reaction over the Ferrospinels, A1-xCuxFe2O4 (A $=\mathrm{Ni}$ or Co and $\mathrm{x}=0,0.3,0.5$, 0.7 and 1), Prepared by 'Soft' Chemical Methods," Journal of Molecular Catalysis A: Chemical, Vol. 187, No. 1, 2002, pp. 105-117.

doi:10.1016/S1381-1169(02)00121-8

[4] S. Ek, et al., "Determination of the Hydroxyl Group Content in Silica by Thermogravimetry and a Comparison with 1HMAS NMR Results," Thermochimica Acta, Vol. 379, No. 1-2, 2002, pp. 201-211. doi:10.1016/S0040-6031(01)00618-9
[5] N. D. Ivanova, S. V. Ivanov, et al., "High Performance Manganese Oxide for CO Oxidation," Russian Journal of Applied Chemistry, Vol. 75, No. 9, 2002, pp. 1420-1423. doi:10.1023/A:1022216626347

[6] L. S. D. Glasser, "Crystallography and Its Applications," Van Nostrand Reinhold Company Ltd., New York, 1977, p. 114.

[7] J. C. Groen, et al., "Pore Size Determination in Modified Micro- and Mesoporous Materials. Pitfalls and Limitations in Gas Adsorption Data Analysis," Microporous and Mesoporous Materials, Vol. 60, No. 1-3, 2003, pp. 1-17. doi:10.1016/S1387-1811(03)00339-1

[8] F, Kapteijn, S. Stegenga, N. J. J. Dekker, J. W. Bijsterbosch and J. A. Moulijn, "Alternatives to Noble Metal Catalysts for Automotive Exhaust Purification," Catalysis Today, Vol. 16, No. 2, 1993, p. 273-287. doi:10.1016/0920-5861(93)85024-T

[9] K. R. Krishnamurthy, B. Viswanathan and M. V. C. Sastri, "Catalytic Oxidation of Carbon Monoxide on Spinel type Ferrites Role of Magnetic Exchange Interactions," Proceedings of Indian National Science Academy, Vol 43, 1977, pp. 34-38.

[10] P. Mars and D. W. Van Krevelen, "Oxidations Carried out by the Means of Vanadium Oxide Catalysts," Chemical Engineering Science, Special Supplement 3, 1954, pp. 41-59. 